\title{
Investigation of the mechanisms of sea spray generation induced by wind-wave interaction in laboratory conditions
}

\author{
Alexander Kandaurov ${ }^{1}$, Daniil Sergeev ${ }^{1 *}$, Yuliya Troitskaya $^{1}$ Olga Ermakova $^{1}$ \\ ${ }^{1}$ Institute of applied physics RAS, Geophysical Research Division, 603950 Ulyanova st. 46, Nizhny Novgorod, Russia
}

\begin{abstract}
The paper presents the results of investigations of the mechanisms of spray of droplets generation within wind wave interaction obtained under laboratory conditions on the High-speed WindWave Flume of the Institute of Applied Physics of the Russian Academy of Sciences. For the research, a multi-angle high-speed video system used together shadow method, including underwater illumination. The results allowed for the classification of mechanismsleading to the formation of droplets. Three main types of phenomena responsible for the generation of the spume droplets near the wave crest were specified: breakage of liquid ligaments, bursting of large submerged bubbles, and bag breakup. The last and less known mechanism claims to be dominant for high wind speeds and it was described in detail.
\end{abstract}

\section{Introduction}

One of the most striking example of multiphase aerodynamic processes in environmenta is the tearing of droplets from wavy water surface under influence of wind friction, which leads to the formation of a sea spray. Sea spray is a typical element of the marine atmospheric boundary layer and is of great importance to marine meteorology, atmospheric chemistry, and climate studies. It is considered a crucial factor in the development of hurricanes and severe extratropical storms, which are responsible for the enhancement of energy flux from the ocean to the atmosphere (see ref. [1-7]). According to the concept of re-entrant spray put forward by Andreas in [1], the contribution of spray to the energy flux is dominated by spume droplets: spray mechanically torn off the crests of breaking waves, which rapidly sediments under the effects of gravity before a significant fraction of its volume has time to evaporate. The spray-mediated momentum flux is also dominated by the spume droplets, which are the main contributors to the volume flux of sea spray as was shown $[8,9]$. However, it remains challenging to arrive at estimates for the efficiency of the spray-mediated fluxes because the number and parameters of spume droplets ejected from the water surface into the atmosphere at high winds are uncertain due to both difficulties in taking measurements under storm conditions and uncertainties in the mechanisms of spray generation. As a result, empirical spray generation functions (SGF), which describe the size spectra of spray ejected per unit area per unit time, can differ for the spume droplets by up to six orders of magnitude in different observations (see compilation of experimental data from $[10,11])$.
In [12] Koga performed the first observations of the process by which spume droplets are generated were reported. This work showed the development of small liquid ligaments, mainly on the crests of breaking waves, that stretch and break, producing one or two droplets. An SGF based on this mechanism was developed in [13]. The second mechanism of sea spray production is via the bursting of bubbles formed at the crests of breaking waves, as studied in [14-20]. Recently, Veron [21] reported on an alternative mechanism: fragmentation of water surface disturbances in the "bag breakup" regime, but it was not described in details.

Present investigation aimed on the observation and detail description of the possible mechanisms of spray generation and development of their classification within one experimental work using novel technique of multiangle high-speed filming with shadow visualization.

\section{Optical scheme and experimental techniques for investigating spray- generating phenomena using the shadow method}

Experiments were performed at the High Speed WindWave Flume of the Institute of Applied Physics of the Russian Academy of Sciences (IAP RAS). The detail description of the facility and the parameters of the air flow and surface waves are described in detail in work [22]. The airflow channel has a cross-section $0.4 \mathrm{~m} \times 0.4$ $\mathrm{m}$ over the water surface and the length of $10 \mathrm{~m}$.

The tank is filled with fresh water, with a temperature ranging from 15 to $20{ }^{\circ} \mathrm{C}$. The processes of spray generation are related to small-scale effects on the water surface. Therefore, to study them, it is important to 
verify the absence of a parasite effect of surfactants dissolved in water. Thus, surface tension was controlled for all experiments and measured value was $\sigma=(7.3 \pm 0.15) 10^{-2} \mathrm{~N} / \mathrm{m}$.

The centerline velocity range was $3-25 \mathrm{~m} / \mathrm{s}$. To characterize the air flow above the water surface, we use the parameters of the atmospheric turbulent boundary layer: the wind friction velocity, $u_{*}$, roughness height, $z_{0}$, and $10-\mathrm{m}$ wind speed $U_{10}$, defined as follows:

$$
U_{10}=\frac{u_{*}}{\kappa} \ln \frac{H_{10}}{z_{0}}
$$

where $\kappa=0.4$ (the von Karman constant) and $H_{10}=10 \mathrm{~m}$. In the wind-wave flume, $U_{10}$ is $7-36 \mathrm{~m} / \mathrm{s}$.

Using the shadow method for visualization, video of the air-water interface was captured by a NAC Memrecam HX-3 high-speed digital video camera from two angles: a top view of the channel at $6.5 \mathrm{~m}$ fetch and a side view at $7.5 \mathrm{~m}$ fetch. For the side view, the camera was placed in a waterproof box attached to the side wall of the channel at $7.5 \mathrm{~m}$ fetch (the horizontal shadow method, Fig. 2). The optical axis of the camera lens was located $5 \mathrm{~cm}$ above the water surface and was directed horizontally. The distance from the camera to the shooting area was $65 \mathrm{~cm}$. A 300-W LED spotlight was mounted at the side of channel section 8 at a distance of $50 \mathrm{~cm}$ from the wall and a height of less than $5 \mathrm{~cm}$ from the surface of the water. A diffuser screen was placed on the side wall of the channel opposite the camera. The $85-\mathrm{mm}$ focal length lens provided an image size of $75 \times$ $66 \mathrm{~mm}(1024 \times 904 \mathrm{px}, 73 \mu \mathrm{m}$ pixel size $)$, the recording rate was $10,000 \mathrm{fps}$, and the exposure time was $50 \mu \mathrm{s}$. Detailed side view records of spray-generating phenomena were obtained for wind speeds $U_{10}$ from 18 $\mathrm{m} / \mathrm{s}$ to $33 \mathrm{~m} / \mathrm{s}$.

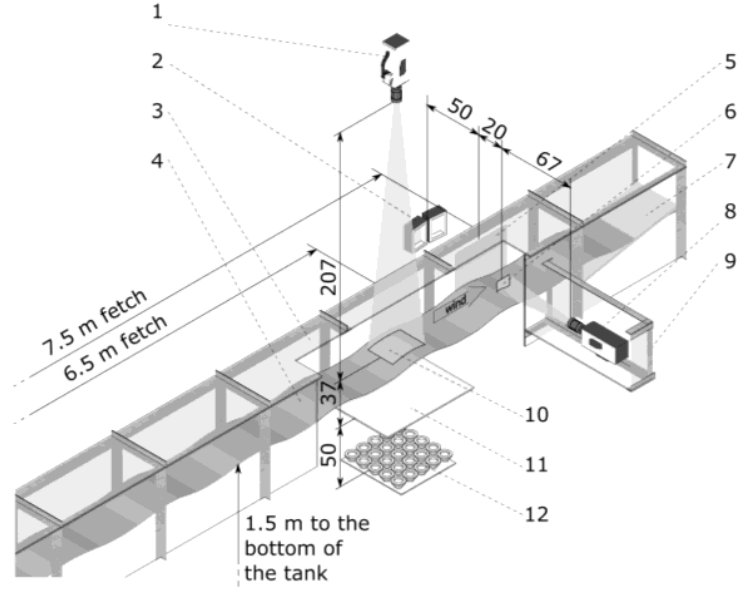

Fig. 1. General scheme of experiment including 1) camera NX3 in top position 2) LED spotlight 3) wind-wave flume 5) opaque screen 6) camera footprint 7) beach 8) camera NX-3 in side position 9) waterproof box 10) camera footprint 11)diffuser screen 12) underwater LED array

To obtain statistics on the spray-generating phenomena, top-view video was filmed using underwater lighting (the vertical shadow method, Fig. $2 b)$. The video was captured through the transparent top wall at $6.5-\mathrm{m}$ fetch. The camera was mounted vertically at a distance of $207 \mathrm{~cm}$ from the water surface. The 85- $\mathrm{mm}$ focal length lens provided an image size of $147 \times$ $377 \mathrm{~mm}(576 \times 1472 \mathrm{px}, 256 \mu \mathrm{m}$ pixel size $)$, the recording rate was $4,500 \mathrm{fps}$.

\section{Classification of phenomena responsible for generation of spume droplets}

Experiments were performed at airflows corresponding to $10-\mathrm{m}$ wind speeds between $18 \mathrm{~m} / \mathrm{s}$ and $33 \mathrm{~m} / \mathrm{s}$ under field conditions according to [23]. The combination of the two shooting angles revealed the phenomena responsible for the generation of spume droplets. Analysis of the images enables us to specify three main types of phenomena responsible for the generation of the spume droplets near the wave crest: breakage of liquid ligaments, bursting of large (approximately 1-cm diameter) submerged bubbles, and bag breakup.

Fig. 2 illustrates the mechanism by which droplets are generated through breakage of liquid ligaments, as discovered and studied by Koga in [12]. According to [12], the Kelvin-Helmholtz instability at the air-water boundary leads to the development of liquid ligaments, mainly at the crests of breaking waves, which stretch and then break into droplets. The details of the structure of the breaking wave crest as shown in insets to Fig. 3e are similar to the structures shown in Fig. 3a-d. Fig. 3b-d confirm that each breakage of a ligament produces a few droplets with diameters of 1-2 $\mathrm{mm}$, which typically fall to the water close to the breaking crest.

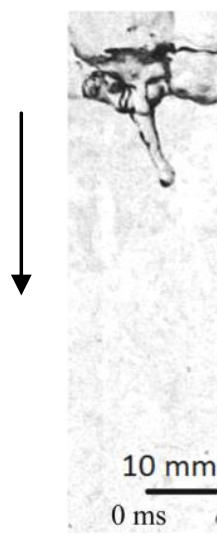

(a)

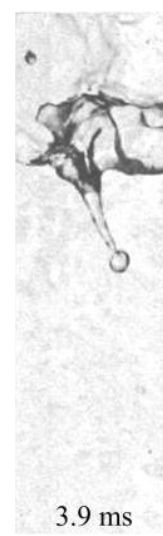

(b)

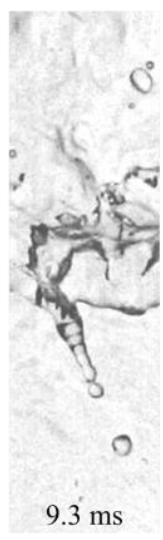

(c)

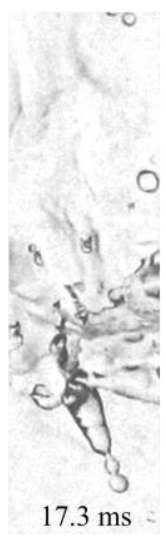

(d)
Fig. 2. Generation of droplets through the development and breakage of liquid ligaments. (a) Stretching of the ligament, $t=0 \mathrm{~ms}$. (b) Formation of the droplet, $t=3.9 \mathrm{~ms}$. (c) Separation of the first droplet and formation of the second, $t=9.3 \mathrm{~ms}$. (d) Formation of the third and fourth droplets, $t=17.3 \mathrm{~ms}$, wind speed $U_{10}=25 \mathrm{~m} / \mathrm{s}$, image dimensions $67.48 \times 101.13 \mathrm{~mm}$. Arrow indicates wind direction.

Entrainment of air at breaking wave crests leads to the formation of a large number of bubbles, which emerge because of their positive buoyancy and burst into droplets as they reach the water surface (Fig. 3). A detailed model of this phenomenon was recently developed by Lhuissier and Villermaux in [20]. The mechanism of the spray production due to bursting of 
smaller bubbles (less than $10 \mu \mathrm{m}$ ) has been studied by Blanchard in [14] and series of investigations performed by Spiel [15-19]. Wu in [24] considered bursting bubbles to be the main source of ocean spray with the radii below $50 \mu \mathrm{m}$. According to experiments [20], bursting of a bubble begins with a local reduction of the film thickness and the formation of a hole. The rim bounding the hole moves along the curved surface of the bubble during its expansion. Resulting centrifugal acceleration causes the development of Rayleigh-Taylor instability, accompanied by the formation of ligaments that fragment into droplets. Fig. 4 from our experiment shows that, in the presence of strong wind and waves at the water surface, the bursting of a submerged bubble touching the water surface occurs as in air and water at rest.

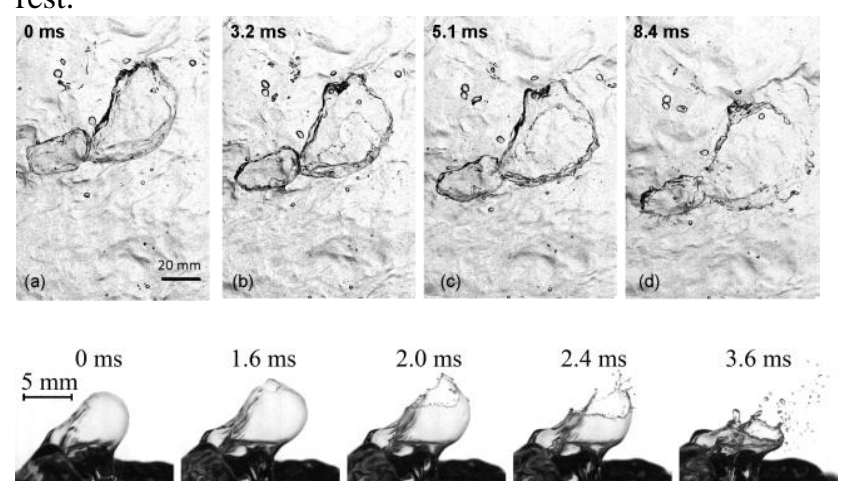

Fig. 3. The burst of a large bubble in strong wind conditions, $U_{10}=25 \mathrm{~m} / \mathrm{s}$. The top panel: (a) The floating bubble, $t=0 \mathrm{~ms}$. (b) Formation of a hole in the liquid film, $t=3.2 \mathrm{~ms}$. (c) Expansion of the hole, $t=5.1 \mathrm{~ms}$. (d) Droplet formation, $t=8.4 \mathrm{~ms}$. The bottom panel is the side view of the bubble burst.

A sequence of top-view (Fig. 4a) and side-view (Fig. $5 b)$ frames from two different videos illustrates another effective mechanism for generating spume droplets at high wind. It starts with an increase in the small-scale elevation of the surface (Fig. $4 \mathrm{a}, 0 \mathrm{~ms}$, Fig. $5 \mathrm{~b}, 0 \mathrm{~ms}$ ), which then transforms into a small liquid "sail", inflates into a canopy bordered by a thicker rim (Fig. 4a, 4.7, 8.2 $\mathrm{ms}$, Fig. 4b, $3.4 \mathrm{~ms}$ ), and finally ruptures to produce spray (Fig. 4a, $10.5 \mathrm{~ms}$, Fig. 4b, $5.6 \mathrm{~ms}$ ). In some cases, the initial elevated area was transformed into a more complex structure comprising several inflating canopies (Fig. 4c-d). The above-described process by which this occurs is well-known in industrial fluid dynamics as the bag breakup regime of liquid fragmentation in gaseous flows (see description given by Gelfand in [25]). This regime of spume droplet generation at the crests of wind waves was recently mentioned by Veron in [21] but was not studied in details. Below, we will use the term "bag" to refer to the observed structure.
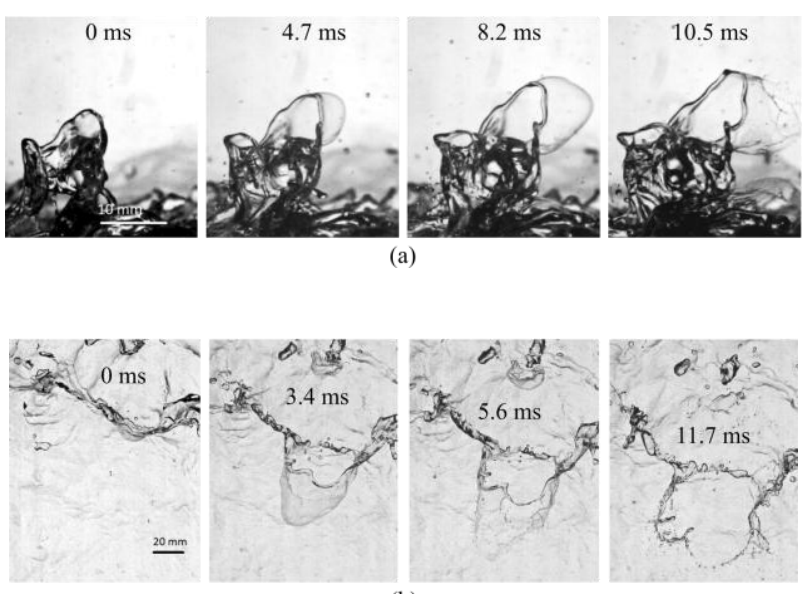

(b)
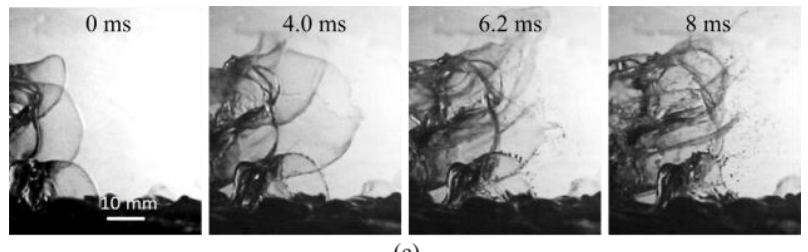

(c)

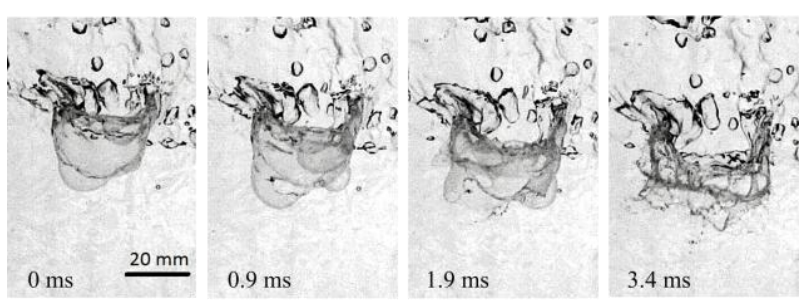

(d)

Fig. 4. The formation and rupture of a bag. A single bag: (a) side view, (b) top view. A "multi-bag": (c) side view, (d) top view. $U_{10}=25 \mathrm{~m} / \mathrm{s}$.

The process of rupture of the canopy looks similar to the process of bubble bursting investigated in [20]: it also involves a hole bounded by a rim (the thin rim). A rim moving along the curved film of the canopy during the expansion of the hole leads to the formation of ligaments and drops through the development of Rayleigh-Taylor instability. We emphasize that the distinguishing feature of a bag from a bubble is the presence of two rims limiting the film. As a result, the size distribution of droplets can be expected to show two typical scales as it is really observed for the real conditions, see ref. [10]. It is the main difference of bag breakup from two previous mechanisms, because liquid ligaments could produces large droplets while bursting bubbles small droplets.

We proposed simple qualitative model for description of fragmentation of the air-water interface in the bag breakup mode similar to droplets in gaseous flows. Fig. 5a-d schematically illustrates the typical stages. Note that research has not yet been able to determine the detailed appearance of the initial disturbance that will be transformed into a bag. In Fig. $5 \mathrm{a}$, it is assumed that the growth of the initial elevation in the water surface is governed by shear flow instability. With the increase of the surface elevation, the airflow 
becomes asymmetrical: the pressure minimum is shifted to the leeward side of the elevated region of water (Fig. $5 b$ ), eventually turning it to a liquid sail (Fig. 5c). This process is similar to the transformation of droplets in gaseous flow into a thin disk moving across the flow. The result is the distortion of the shape of the elevated region of water, leading to inflation of the canopy (Fig. 5d), which then raptures (Fig. 5e) and bursts, producing spray.

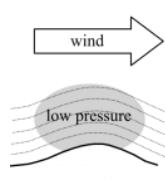

(a)

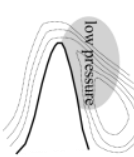

(b)

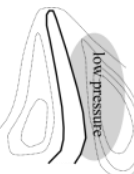

(c)

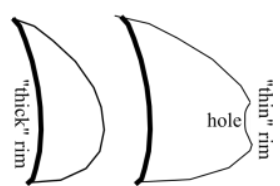

(e)
Fig. 5. Schematic diagram of the formation and fragmentation of a bag. (a) Formation of the initial disturbance, (b) increase of the initial disturbance, (c) sail-shaped disturbance, (d) formation of the bag, (e) rupture of the bag. The thin dotted lines are the streamlines in the reference frame following the elevation of the water surface.

The preliminary statistical analysis shows that bag breakup appears to be the dominant mechanism of spume droplet generation at high winds for our laboratory experiment.

For the bag breakup events, the special software was developed which enables to obtain the geometrical and kinematic parameters of the objects (see. Fig. 6), including the initial size, $D_{1}$, of the bag, defined as the distance between edge markers in a frame showing the nucleation of the bag; the bag final size, $D_{2}$, defined as the distance between edge markers in a frame showing film puncture; and the bag lifetime from the moment of its nucleation until the moment of film puncture, $\tau$. The velocities of the bag edges and center, $\mathrm{u}_{1}$, and $\mathrm{u}_{2}$, were calculated as the distance between, respectively, the midpoints of edge markers or the centers of the canopy on the initial and final frames, divided by $\tau$.
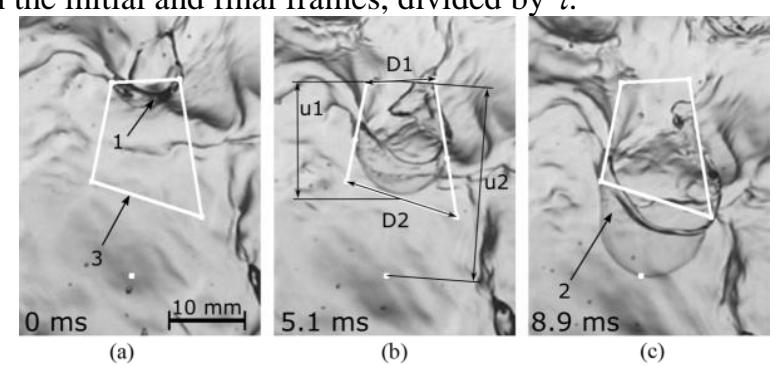

Fig. 6. Semi-automatic registering of the evolution of a bag: (a) initial frame showing bag nucleation, (b) intermediate frame with annotated markers, edge positions are interpolated, (c) final frame showing the moment of canopy puncture. 1- bag nucleation, 2 - canopy puncture, 3 - manually defined markers. The friction velocity of the airflow is $1.04 \mathrm{~m} / \mathrm{s}$, and the average wind direction is from top to bottom.

\section{Conclusion}

This paper focuses on the mechanisms of production of spume droplets, i.e., sea spray torn off wave crests by wind. The study is based on laboratory experiments in a
High-speed Wind-wave Flume, where measurements were performed with airflows corresponding to $10-\mathrm{m}$ wind speeds between $18 \mathrm{~m} / \mathrm{s}$ and $33 \mathrm{~m} / \mathrm{s}$ for field conditions. According to data from [26, 27], this corresponds to the typical range of turbulent shear stresses observed in the turbulent boundary layer under severe tropical storm and hurricane conditions. Highspeed video capture enabled us to investigate how droplets are torn from the crests of surface waves. Since the typical timescale of this process is a few milliseconds, frame rates from $4,500 \mathrm{fps}$ to $10,000 \mathrm{fps}$ were used. Capturing video from two directions (side and top view) enabled us to study the process of spume droplet generation in detail. The video revealed that the generation of spume droplets near the wave crest is caused by several local phenomena. It is possible to classify the observed phenomena into three types. One is the development of liquid ligaments, mainly on the crests of breaking waves, which stretch and then break into droplets. A second is the production of spume droplets through the bursting of submerged bubbles. The third effective mechanism of spume droplet generation. During a bag breakup event, an increase in the smallscale elevation of the water surface results in the formation of a kind of small sail, which is then inflated into a canopy bordered by a thicker rim and finally ruptures to produce spray. Preliminary analysis of the videos showed that bag breakup claim to be dominant mechanism of spume droplet generation at high winds. Special software developed for analysis of the geometrical and kinematic parameters of the bags will help to obtain statistical parameters of these objects in further investigations.

Carrying out experiments themselves was supported by Russian Science Foundation (Agreement No. 14-17-00667); designing of methods of measurements including: optical and visualization scheme, methods of measurements of the air flow and wave field parameters were supported by Russian Foundation of Basic Research (No 18-55-50005, 18-05-60299, 16-05-00839); the development of the software was supported by the Grant of the President no. MK-2041.2017.5, and the work under processing of the video was supported by Russian Science Foundation (Agreement No. 18-77-00074).

\section{References}

1. E. L. Andreas J. Atmos. Sci. 68, 1435 (2011)

2. Andreas, E. L., K. A. Emanuel, J. Atmos. Sci. 58, $3741(2001)$

3. J.W. Bao, C. W. Fairall, S. A. Michelson L. Bianco, Mon. Weather Rev., 139, 3781 (2011).

4. L. Bianco, J.W. Bao, C. W. Fairall S. A. Michelson, Bound.-Layer Meteor. 140, 361 (2011)

5. A. V Soloviev, R. Lukas, M. Donelan, B. K. Haus, I. Ginis, Sci. Rep. 4, 5306 (2014).

6. N. Takagaki, S. Komori, N. Suzuki, K. Iwano, R. Kurose, Geophys. Res. Lett. 43, 9829 (2016)

7. N. Takagaki, S. Komori, M. Ishida, K. Iwano, R. Kurose, N. Suzuki, J. Atmos. Oceanic Technol. 34, 2129 (2017) 
8. C. W. Fairall, M. L. Banner, W. L. Peirson, W. Asher, R. P. Morison, J. Geophys. Res. Ocean. 114, C10001 (2009)

9. E. L. Andreas. J. Phys. Oceanogr. 28, 2175 (1998).

10. F. Veron, Annu. Rev. Fluid Mech. 47, 507 (2015)

11. E. L. Andreas, Atmosphere-Ocean Interactions WIT Press, 1, 1 (2002).

12. M. Koga, Tellus. 33, 552 (1981).

13. J. A. Mueller, F. Veron, A Sea State-Dependent Spume Generation Function. J. Phys. Oceanogr. 39, 2363 (2009).

14. D. C. Blanchard, Prog. Oceanogr., 1, 71 (1963).

15. D. E. Spiel, J. Geophys. Res. 99, 10289 (1994).

16. D. E. Spiel, Tellus B, 46, 4, 325 (1994).

17. D. E. Spiel, J. Geophys. Res. 100, 4995 (1995)

18. D. E. Spiel, J. Geophys. Res. 102, 5815 (1997).

19. D. E. Spiel, J. Geophys. Res., 103, 24907 (1998).

20. H. Lhuissier, E. Villermaux, J. Fluid Mech. 696, 5 (2012).

21. F. Veron, C. Hopkins, E. L. Harrison, and J. A. Mueller. Geophys. Res. Lett. 39, L16602 (2012).

22. Yu. I. Troitskaya, D.A. Sergeev, A.A. Kandaurov, G.A Baidakov, M.A. Vdovin, V.I. Kazakov J. Geophys. Res, 117, C00J21 (2012)

23. R. J. Foreman, S. Emeis J. Phys. Oceanogr. 40, 2325 (2010).

24. J. Wu, Evidence of sea spray produced by bursting bubbles. Science. 212, 324 (1981).

25. B. E. Gelfand, Prog. Energ. Combust. Sci. 22, 201 (1996).

26. M. D. Powell, P. J. Vickery, T. A. Reinhold . Nature, 422, 279 (2003).

27. D. H. Richter, R. Bohac, D. P. Stern, J. Atmos. Sci. 73, 2665 (2016). 